\title{
THE
}

$12-4-2018$

\section{Synergistic Performance of Lithium Difluoro(oxalato)borate and Fluoroethylene Carbonate in Carbonate Electrolytes for Lithium Metal Anodes}

\author{
Zachary L. Brown \\ University of Rhode Island \\ Brett L. Lucht \\ University of Rhode Island, blucht@uri.edu
}

Follow this and additional works at: https://digitalcommons.uri.edu/chm_facpubs

Creative Commons License

\section{(c) (i)}

This work is licensed under a Creative Commons Attribution 4.0 License.

\section{Citation/Publisher Attribution}

Brown, Z.L., \& Lucht, B.L. (2019). Synergistic Performance of Lithium Difluoro(oxalato)borate and Fluoroethylene Carbonate in Carbonate Electrolytes for Lithium Metal Anodes. Journal of The Electrochemical Society, 166(3) A5117-A5121 doi: 10.1149/2.0181903jes

Available at: http://dx.doi.org/10.1149/2.0181903jes

This Article is brought to you for free and open access by the Chemistry at DigitalCommons@URI. It has been accepted for inclusion in Chemistry Faculty Publications by an authorized administrator of DigitalCommons@URI. For more information, please contact digitalcommons-group@uri.edu. 


\title{
Synergistic Performance of Lithium Difluoro(oxalato)borate and Fluoroethylene Carbonate in Carbonate Electrolytes for Lithium Metal Anodes
}

\author{
Zachary L. Brown $\circledast^{*}$ and Brett L. Lucht $\oplus^{* *, z}$ \\ Department of Chemistry, University of Rhode Island, Kingston, Rhode Island 02881, USA
}

\begin{abstract}
There is significant interest in the development of rechargeable high-energy density batteries which utilize lithium metal anodes. Recently, fluoroethylene carbonate (FEC) and lithium difluoro(oxalato)borate (LiDFOB) have been reported to significantly improve the electrochemical performance of lithium metal anodes. This investigation focuses on exploring the synergy between LiDFOB and FEC in carbonate electrolytes for lithium metal anodes. In ethylene carbonate (EC) electrolytes, LiDFOB is optimal when used in high salt concentrations, such as $1.0 \mathrm{M}$, to improve the electrochemistry of the lithium metal anode in $\mathrm{Cu}|| \mathrm{LiFePO}_{4}$ cells. However, in FEC electrolytes, LiDFOB is optimal when used in lower concentrations, such as $0.05-0.10 \mathrm{M}$. From surface analysis, LiDFOB is observed to favorably react on the surface of lithium metal to improve the performance of the lithium metal anode, in both EC and FEC-based electrolytes. This research demonstrates progress toward developing feasible high-energy density lithium-based batteries. (c) The Author(s) 2018. Published by ECS. This is an open access article distributed under the terms of the Creative Commons Attribution 4.0 License (CC BY, http://creativecommons.org/licenses/by/4.0/), which permits unrestricted reuse of the work in any medium, provided the original work is properly cited. [DOI: 10.1149/2.0181903jes]

(cc) BY
\end{abstract}

Manuscript submitted September 26, 2018; revised manuscript received November 21, 2018. Published December 4, 2018. This paper is part of the JES Focus Issue of Selected Papers from IMLB 2018.

The development of energy storage technology is an important topic for facilitating the employment of renewable energy in society. Therefore, current energy storage research is heavily focused on enabling rechargeable high-energy density lithium-based batteries. ${ }^{1-3}$ In particular, permitting reversible electrochemical plating and stripping of the lithium metal anode in carbonate electrolytes can achieve this goal. ${ }^{4}$ Unfortunately, the performance of the lithium metal anode in carbonate electrolytes is plagued by unsafe dendrite formation and poor Coulombic efficiency upon cycling. However, recent developments in electrolyte chemistry have improved upon these limitations significantly. 2,3

Fluoroethylene carbonate (FEC) containing electrolytes have been reported to improve the performance of lithium metal electrodes via the generation of polymeric species and LiF within the Solid Electrolyte Intephase (SEI), ${ }^{5}$ similar to that reported for silicon anodes, which may contribute to the improved cycling performance of lithium metal anodes. ${ }^{6-9}$ Recent work suggests that reduction of FEC generates nano-structured $\mathrm{LiF}$, creating a uniform diffusion field on the lithium metal electrode, leading to uniform plating and stripping. ${ }^{9}$ Furthermore, it has been demonstrated that employing FEC in cosolvent amounts is optimal for achieving high performance lithium metal anodes. ${ }^{6}$

Lithium difluoro(oxalato)borate (LiDFOB) has also been reported to generate nano-structured $\mathrm{LiF}$ for lithium metal electrodes, thereby improving the electrochemical performance of the lithium metal anode. ${ }^{10}$ However, the optimal amount of LiDFOB to use in carbonate electrolytes for the lithium metal anode has not been explored. Further, the synergy between FEC and LiDFOB has not been investigated in carbonate electrolytes for the lithium metal anode. Given the reported improvement in plating/stripping of the lithium metal anode with FEC and LiDFOB containing electrolytes, exploring their synergy can assist researchers in developing high performance electrolytes for the lithium metal anode.

Several carbonate electrolyte compositions containing FEC and LiDFOB have been investigated via a combination of electrochemical analysis with $\mathrm{Cu}|| \mathrm{LiFePO}_{4}$ cells and ex-situ surface analysis of the cycled electrodes. The in-situ formation of lithium metal and low reactivity of $\mathrm{LiFePO}_{4}$ in $\mathrm{Cu}|| \mathrm{LiFePO}_{4}$ cells ensure that FEC does not react with the electrode surfaces prior to the initial lithium plating cy- cle, as previously reported..$^{9,11}$ In particular, ex-situ diffuse reflectance infrared Fourier transform spectroscopy (DRIFTS), and X-ray photoelectron spectroscopy (XPS) were used to confirm the role of LiDFOB in the optimized electrolytes. The analysis reveals that LiDFOB can be used in additive concentrations to work synergistically with FEC co-solvent electrolytes.

\section{Experimental}

Electrochemistry.-Electrochemical characterization was performed using $\mathrm{Cu}|| \mathrm{LiFePO}_{4} 2032$ coin cells. The $\mathrm{Cu}|| \mathrm{LiFePO}_{4}$ cells were assembled with a $\mathrm{Cu}$ metal foil negative electrode $(15 \mathrm{~mm}$ diameter, MTI Corporation), two Celgard 2400 separators (19 mm diameter), and a $\mathrm{LiFePO}_{4}$ positive electrode (91\% active material, $13.7 \mathrm{~mm}$ diameter, MTI corporation), the other $9 \%$ of the composite electrode is composed of conductive carbon and PVDF coated on aluminum. The cells were prepared with $60 \mu \mathrm{L}$ of electrolyte. Electrolytes investigated include (1-x) $\mathrm{M} \mathrm{LiPF}_{6}+\mathrm{x} \mathrm{M} \mathrm{LiDFOB}$ in ethylene carbonate: dimethyl carbonate (1g:4g, EC:DMC) solvent and (1-x) $\mathrm{M} \mathrm{LiPF}_{6}+\mathrm{x}$ M LiDFOB in fluoroethylene carbonate: dimethyl carbonate (1g:4g, FEC:DMC) solvent. The compositions studied consist of 1.0 M LiPF 6 , (1.0 M LiPF 6 EC electrolyte), 0.95 $\mathrm{M} \mathrm{LiPF}_{6}+$ $0.05 \mathrm{M}$ LiDFOB (0.05 M LiDFOB EC electrolyte), $0.90 \mathrm{M} \mathrm{LiPF}_{6}$ $+0.10 \mathrm{M}$ LiDFOB (0.10 M LiDFOB EC electrolyte), $0.50 \mathrm{M} \mathrm{LiPF}_{6}$ $+0.50 \mathrm{M}$ LiDFOB (0.50 M LiDFOB EC electrolyte), and $1.0 \mathrm{M}$ LiDFOB (1.0 M LiDFOB EC electrolyte). Comparable compositions studied in FEC:DMC electrolytes are abbreviated as $1.0 \mathrm{M} \mathrm{LiPF}_{6}$ FEC electrolyte, 0.05 M LiDFOB FEC electrolyte, 0.1 M LiDFOB FEC electrolyte, 0.5 M LiDFOB FEC electrolyte, and 1.0 M LiDFOB FEC electrolyte. The copper metal foil was sonicated with isopropanol (2 $\times 2$ minutes), punched to the specified diameter, and dried at $110^{\circ} \mathrm{C}$, overnight under vacuum prior to cell assembly. The $\mathrm{LiFePO}_{4}$ electrodes were punched to the specified diameter, and dried at $110^{\circ} \mathrm{C}$ overnight under vacuum prior to cell assembly. The cycling procedure consisted of plating Li metal at $0.1 \mathrm{~mA} / \mathrm{cm}^{2}$ (approx. $\mathrm{C} / 20$ rate, where $\mathrm{C}$ represents the theoretical capacity of $\mathrm{LiFePO}_{4}$ ) with subsequent stripping and plating at $0.4 \mathrm{~mA} / \mathrm{cm}^{2}$ (approx. $\mathrm{C} / 4$ rate), within a voltage window of 2.0-4.0 V, using an Arbin BT2000 battery cycler at $25^{\circ} \mathrm{C}$. There was a rest period of one hour between cell construction and the beginning of the electrochemical protocol.

DRIFTS.-IR spectra of lithium metal electrodes were acquired with a Bruker Tensor 27 spectrometer equipped with an UpIR 
Diffuse Reflectance accessory (Pike Technologies) and LaDTG detector. Lithium metal was deposited onto $\mathrm{Cu}$ foil according to the first charge procedure outlined in the electrochemistry section (charge to $4.0 \mathrm{~V}$ at $\mathrm{C} / 20$ rate) and held at rest for approximately 4 hours to ensure cell equilibration before disassembly. Electrodes were washed with 4 $\times 500 \mu \mathrm{L}$ battery grade DMC and dried under vacuum for $20 \mathrm{~min}$ utes, then stored overnight in an argon-filled glove box. The electrodes were transferred from an argon glove box to a nitrogen-filled glove box in a sealed Nalgene vial and measured immediately with DRIFTS. There is no evidence for reaction of the lithium metal anodes with $\mathrm{N}_{2}$ during the timeframe of the analysis. The spectra were acquired in the nitrogen glove box with a resolution of $4 \mathrm{~cm}^{-1}$ and 32 scans.

XPS._XPS measurements were acquired with a K-alpha Thermo system using $\mathrm{Al} \mathrm{K} \alpha$ radiation $(\mathrm{h} \nu=1486.6 \mathrm{eV}$ ) under ultra-high vacuum $\left(<1 \times 10^{-12} \mathrm{~atm}\right)$ and a measured spot size of $400 \mu \mathrm{m}$ in diameter. Lithium metal was deposited onto $\mathrm{Cu}$ foil according to the first charge procedure outlined in the electrochemistry section (charge to $4.0 \mathrm{~V}$ at $\mathrm{C} / 20$ rate), and held at rest for approximately 4 hours to ensure cell equilibration before disassembly. Electrodes were washed with $4 \times 500 \mu \mathrm{L}$ battery grade DMC and dried under vacuum for 10 minutes, then overnight in the argon glove box. The samples were transferred from the argon glove box in an air-free transfer case, while sealed under vacuum. The binding energy was corrected based on the F1s spectrum, assigning $\mathrm{LiF}$ to $685 \mathrm{eV}$.

\section{Results}

The concentration of $\mathrm{Li}^{+}$is maintained at $1.0 \mathrm{M}$ for all electrolytes investigated, emphasizing the influence of the $\mathrm{PF}_{6}{ }^{-}$and $\mathrm{DFOB}^{-}$anions on electrochemical performance. The stripping capacity vs. cycle number, Coulombic efficiency vs. cycle number and sum of reversibly cycled lithium for $\mathrm{Cu}|| \mathrm{LiFePO}_{4}$ cells after 50 cycles for the EC:DMC electrolytes investigated are provided in Figures $1 \mathrm{~A}, 1 \mathrm{~B}$, and $1 \mathrm{C}$, respectively. The stripping capacity of the cells containing the $1.0 \mathrm{M}$ $\mathrm{LiPF}_{6}$ EC electrolyte (see electrolyte abbreviations in experimental section) is extremely poor, with no significant reversible capacity upon cycling (Fig. 1A), as evidenced by the low initial Coulombic efficiency of $15 \%$. In general, the cycling performance is improved as the concentration of LiDFOB is increased in the electrolyte, with the 1.0 M LiDFOB EC electrolyte having the best performance, achieving 30 cycles before the cell drops below $20 \%$ of the initial capacity (Fig. 1A). This trend is evident in Fig. 1B, with initial efficiencies of 52\%, $69 \%, 87 \%$, and $89 \%$ for the $0.05 \mathrm{M}$ LiDFOB EC, $0.10 \mathrm{M}$ LiDFOB EC, $0.50 \mathrm{M}$ LiDFOB EC, and 1.0 M LiDFOB electrolytes, respectively. The improvement in electrochemical performance is further illustrated by the sum of the stripping capacities (reversibly cycled lithium) over 100 cycles, ${ }^{11}$ which increases with increasing LiDFOB content in the electrolyte (Fig. 1C). With EC-containing electrolytes, it is optimal to use LiDFOB as the pure salt instead of as an additive, supporting previous investigations of LiDFOB electrolytes. ${ }^{9}$

The stripping capacity vs. cycle number, Coulombic efficiency vs. cycle number and sum of reversibly cycled lithium for $\mathrm{Cu}|| \mathrm{LiFePO}_{4}$ cells after 100 cycles for the FEC:DMC electrolytes investigated are provided in Figures 2A, 2B, and 2C, respectively. The $1.0 \mathrm{M} \mathrm{LiPF}_{6}$ FEC electrolyte, out performs all EC electrolytes described above, achieving 40 cycles before the cells drops below $20 \%$ of the initial capacity and higher efficiencies stabilizing around 98\% (Figs. 2A, 2B), consistent with previous work. ${ }^{6,9}$ This is also evident in Figure $2 \mathrm{C}$, since the quantity of reversibly cycled lithium exceeds the best EC electrolyte by more than $1000 \mathrm{mAh} / \mathrm{g}$. Upon addition of LiDFOB to the electrolyte, there are minor improvements in Coulombic efficiency, extending the lifetime of the cell for more cycles (Figs. 2A, 2B). This observation suggests that, upon incorporation of LiDFOB into the electrolyte, parasitic reactions of the lithium metal electrode with the electrolyte are mitigated. The optimal concentration of LiDFOB required is lower for the FEC electrolytes, with the $0.05 \mathrm{M}$ LiDFOB FEC and 0.10 M LiDFOB FEC electrolytes having slightly better electrochemical performance. This trend is also clear for the
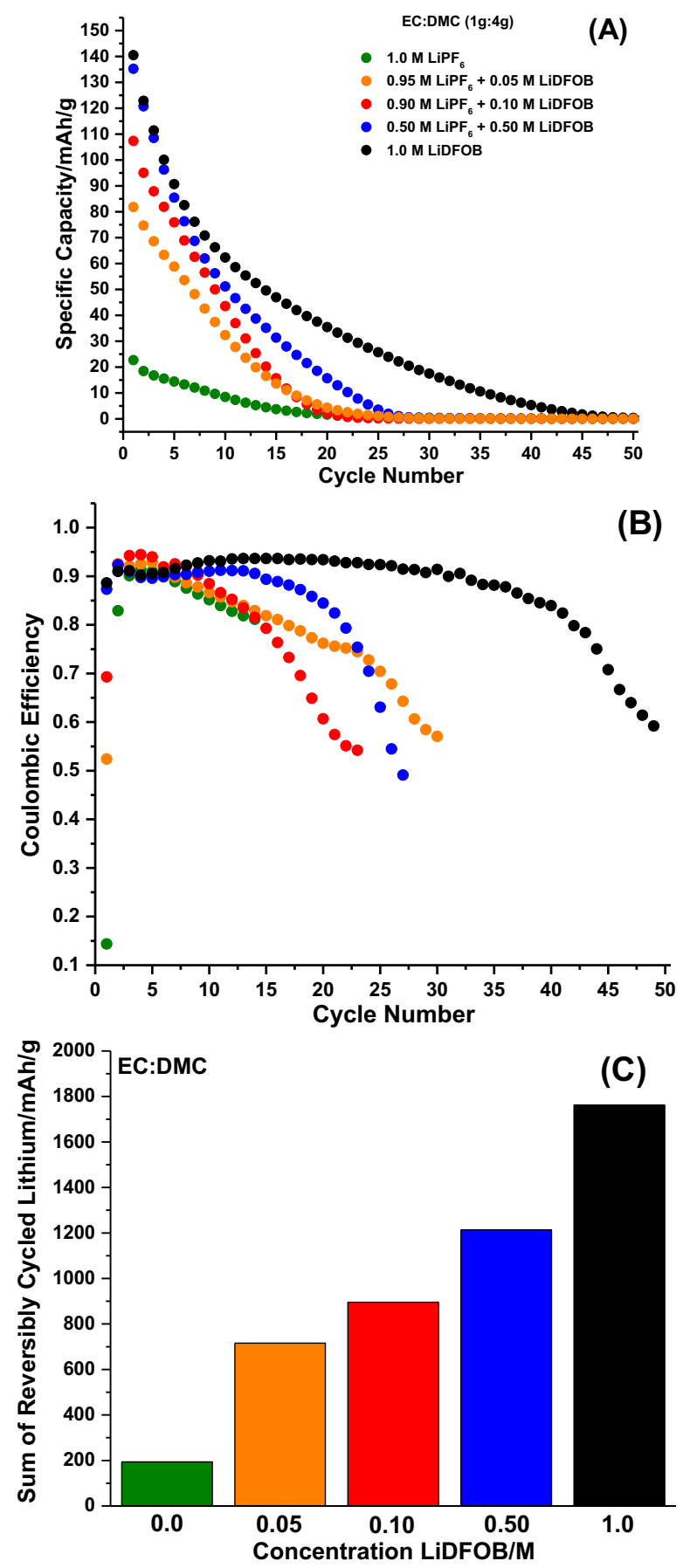

Figure 1. The stripping capacity vs. cycle number (A), Coulombic efficiency vs. cycle number (B), and sum of reversibly cycled lithium (C) for EC:DMC electrolyes in $\mathrm{Cu}|| \mathrm{LiFePO}_{4}$ cells after 50 cycles.

sum of reversibly cycled lithium (Fig. 2C). Therefore, incorporation of LiDFOB in additive concentrations to FEC based electrolytes improves performance synergistically with FEC to improve the cycling performance of the lithium metal anode.

The DRIFTS spectra of the lithium electrode after the first plating cycle of lithium from 1.0 $\mathrm{M} \mathrm{LiPF}_{6}$ EC, $1.0 \mathrm{M} \mathrm{LiDFOB} \mathrm{EC,} 1.0 \mathrm{M}$ $\mathrm{LiPF}_{6}$ FEC, and $0.10 \mathrm{M}$ LiDFOB FEC electrolytes, are provided in Figure 3. The peak at $1573 \mathrm{~cm}^{-1}$ is an artifact peak of the DRIFTS accessory. ${ }^{9}$ The DRIFTS spectrum of the lithium electrode plated with 1.0 $\mathrm{M} \mathrm{LiPF}_{6} \mathrm{EC}$, and 1.0 $\mathrm{M} \mathrm{LiPF}_{6} \mathrm{FEC}_{\text {after the first plating cycle }}$ contains major peaks assigned to lithium carbonate $\left(\mathrm{Li}_{2} \mathrm{CO}_{3} ; 1510\right.$, $\left.1460 \mathrm{~cm}^{-1}\right)$ and lithium alkyl carbonates $\left(\mathrm{ROCO}_{2} \mathrm{Li} ; 1690 \mathrm{~cm}^{-1}\right)$, as 

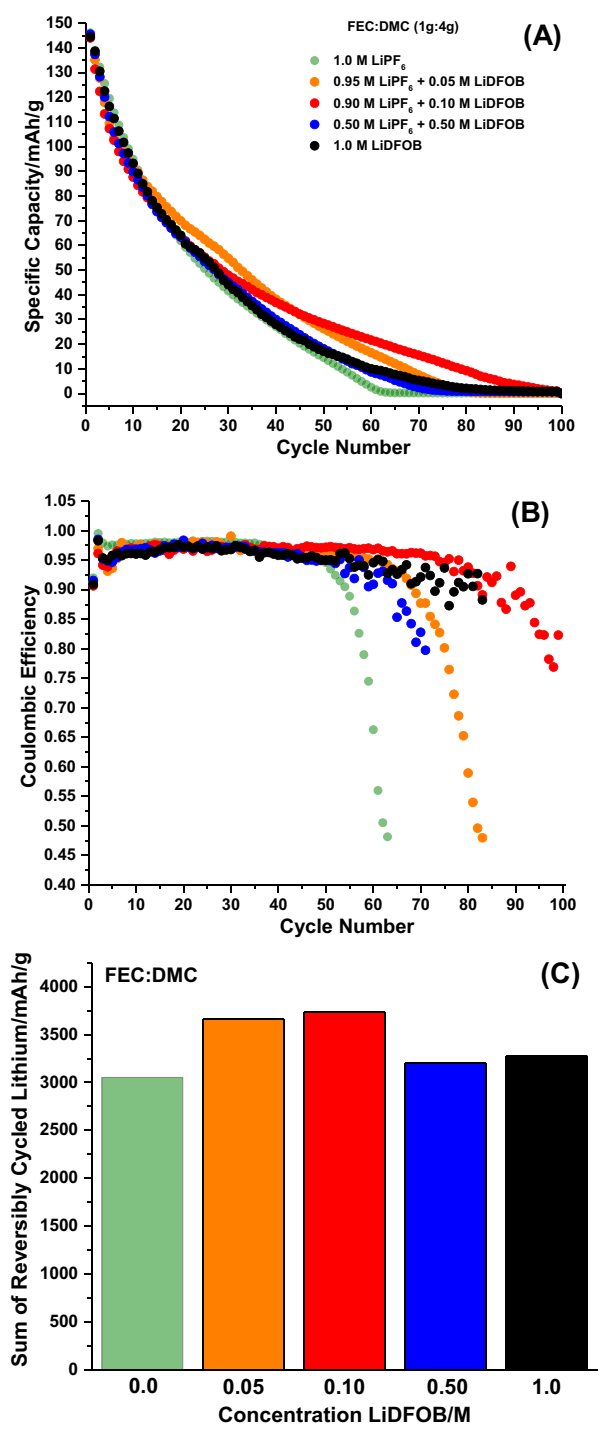

Figure 2. The stripping capacity vs. cycle number (A), Coulombic efficiency vs. cycle number (B), and sum of reversibly cycled lithium (C) for FEC:DMC electrolyes in $\mathrm{Cu}|| \mathrm{LiFePO} 4$ cells after 100 cycles.

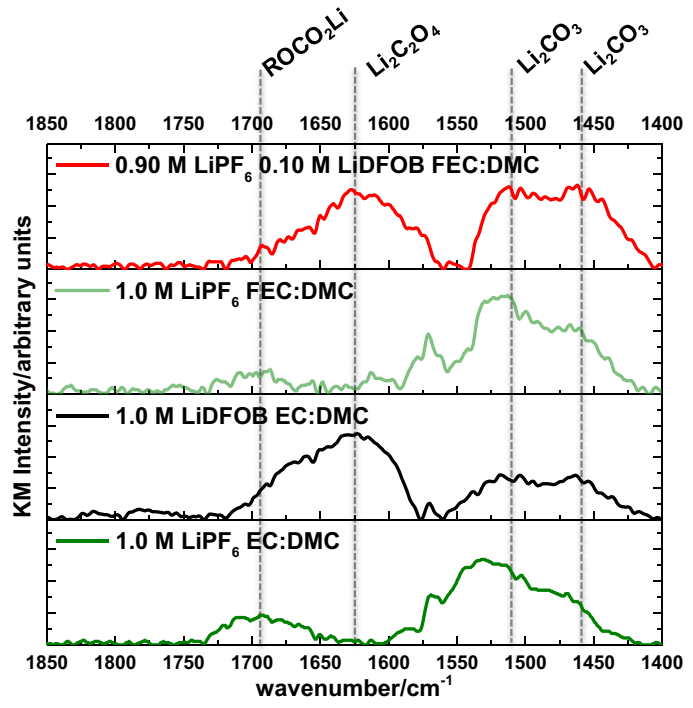

Figure 3. DRIFTS of lithium metal plated with the investigated electrolytes. previously reported. ${ }^{9,12-15}$ The peaks associated with $\mathrm{ROCO}_{2} \mathrm{Li}$ and $\mathrm{Li}_{2} \mathrm{CO}_{3}$ have comparable intensity, suggesting comparable concentrations of these two SEI components for lithium metal plated with both 1.0 $\mathrm{M} \mathrm{LiPF}_{6} \mathrm{EC}$ and FEC electrolytes, consistent with previous work. ${ }^{9}$ The similar IR spectra for lithium plated with the 1.0 $\mathrm{M} \mathrm{LiPF}_{6} \mathrm{EC}$ and FEC but significant difference in cycling performance have been discussed previously, suggesting that the nanostructure of the SEI products is a major factor in electrochemical performance. .,10 $^{9}$

For lithium metal plated with 1.0 M LiDFOB EC and $0.10 \mathrm{M}$ LiDFOB FEC electrolytes, $\mathrm{Li}_{2} \mathrm{CO}_{3}$ is observed, along with similar concentration of $\mathrm{Li}_{2} \mathrm{C}_{2} \mathrm{O}_{4}$ species $\left(1625 \mathrm{~cm}^{-1}\right){ }^{16,17}$ This observation supports the favorable decomposition of LiDFOB on the electrode surface. There also appears to be a minor amount of polycarbonates observed at 1780 and $1815 \mathrm{~cm}^{-1}$, as well, suggesting LiDFOB facilitates the decomposition of EC, consistent with previous work. ${ }^{17}$ There is a relatively higher concentration of $\mathrm{Li}_{2} \mathrm{C}_{2} \mathrm{O}_{4}$ for lithium metal plated with the LiDFOB EC electrolyte compared to the 0.10 M LiDFOB FEC electrolyte, consistent with the significant difference in concentration of LiDFOB in the respective electrolytes. Given that $\mathrm{ROCO}_{2} \mathrm{Li}$ is not observed for lithium plated with the superior LiDFOB electrolytes, the generation of $\mathrm{Li}_{2} \mathrm{C}_{2} \mathrm{O}_{4} / \mathrm{Li}_{2} \mathrm{CO}_{3}$ in the SEI products may be preferential to the generation of $\mathrm{ROCO} \mathrm{Li}_{2} / \mathrm{Li}_{2} \mathrm{CO}_{3}$ in the SEI. This could be due to the poor stability of $\mathrm{ROCO}_{2} \mathrm{Li}$ or the ability of $\mathrm{Li}_{2} \mathrm{C}_{2} \mathrm{O}_{4}$ and $\mathrm{Li}_{2} \mathrm{CO}_{3}$ to control the growth of $\mathrm{LiF}$ nano-particles, as previously reported. ${ }^{9,10}$

The C1s, O1s, and F1s XPS spectra of the lithium electrode after the first plating cycle of lithium from the $1.0 \mathrm{M} \mathrm{LiPF}_{6} \mathrm{EC}, 1.0 \mathrm{M}$

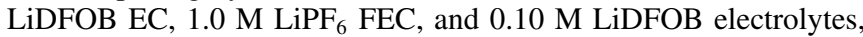
are provided in Figure 4. After the first plating cycle, the $\mathrm{C} 1 \mathrm{~s}, \mathrm{O} 1 \mathrm{~s}$, and F1s spectra are very similar for the lithium metal electrode plated from the 1.0 $\mathrm{M} \mathrm{LiPF}_{6}$ EC and FEC electrolytes, consistent with previous work. ${ }^{9}$ The $\mathrm{C} 1$ s spectra contain peaks associated with $\mathrm{CO}_{3}$ at 289.9 $\mathrm{eV}, \mathrm{C}-\mathrm{O}$ at $286.7 \mathrm{eV}$ and $\mathrm{C}-\mathrm{C} / \mathrm{C}-\mathrm{H}$ at $285.0 \mathrm{eV}$ consistent with the generation of a combination of $\mathrm{ROCO}_{2} \mathrm{Li}$ and $\mathrm{Li}_{2} \mathrm{CO}_{3}$, as observed by IR spectroscopy. ${ }^{11,13,18}$ The O1s spectrum contains a broad beak centered at $\sim 531.8 \mathrm{eV}$, consistent with a mixture of $\mathrm{C}-\mathrm{O}$ and $\mathrm{C}=\mathrm{O}$ containing species. ${ }^{11,13,18}$ A peak for $\mathrm{Li}_{2} \mathrm{O}$ is also observed at $528 \mathrm{eV}$ in the O1s spectrum. ${ }^{11,13,18}$ Further, The F1s spectra are very similar, containing peaks at $685 \mathrm{eV}$ and $687 \mathrm{eV}$ consistent with $\mathrm{LiF}$ and $\mathrm{Li}_{\mathrm{x}} \mathrm{PF}_{\mathrm{y}} \mathrm{O}_{\mathrm{z}}$, respectively. ${ }^{18,19}$ All of these observations are consistent with previous work. ${ }^{9}$

The XPS spectra of the lithium metal plated from the 1.0 M LiDFOB EC electrolyte, contains $\mathrm{C} 1 \mathrm{~s}$ and $\mathrm{O} 1 \mathrm{~s}$ peaks at $289.3 \mathrm{eV}$ and $533.0 \mathrm{eV}$, respectively, consistent with the presence of oxalate functional groups, as observed in the DRIFTS spectrum. ${ }^{10}$ Further, $\mathrm{Li}_{2} \mathrm{O}$ is not observed in the O1s spectrum. The F1s spectrum contains a peak consistent with $\mathrm{LiF}$ although the concentration of $\mathrm{F}$ is relatively low, $8 \%$, suggesting the oxalate products are dominant on the surface. A high concentration of LiDFOB (1 M) was used in the electrolyte, thus the concentration of oxalate species on the surface of lithium metal is expected to be relatively high, consistent with the DRIFTS analysis.

For lithium plated from the $0.10 \mathrm{M}$ LiDFOB FEC electrolyte, the spectra have similarities to both the lithium plated from the $1.0 \mathrm{M}$

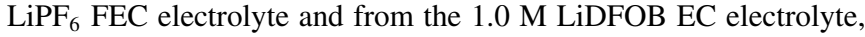
as expected, since the electrolyte contains both LiDFOB and FEC. A C1s peak is observed at $289.0 \mathrm{eV}$, consistent with the presence of $\mathrm{Li}_{2} \mathrm{C}_{2} \mathrm{O}_{4}$ as observed in the DRIFTS spectra. ${ }^{10}$ The O1s spectrum contains a broad peak centered at $532 \mathrm{eV}$ consistent with a combination of $\mathrm{C}-\mathrm{O}$ and $\mathrm{C}=\mathrm{O}$ containing species. ${ }^{11,13,18}$ The observations are slightly different to that of lithium plated from the 1.0 M LiDFOB EC electrolyte, consistent with a lower concentration of LiDFOB decomposition products on the surface of lithium, which is expected for lithium metal plated with the $0.10 \mathrm{M}$ LiDFOB FEC electrolyte since there is a lower concentration of LiDFOB.

Finally, the $\mathrm{B} 1 \mathrm{~s}$ and $\mathrm{P} 2 \mathrm{p}$ spectra are provided in Figure 5 supporting the presence of LiDFOB decomposition products on the surface of lithium metal plated from the LiDFOB containing electrolytes. Peaks 

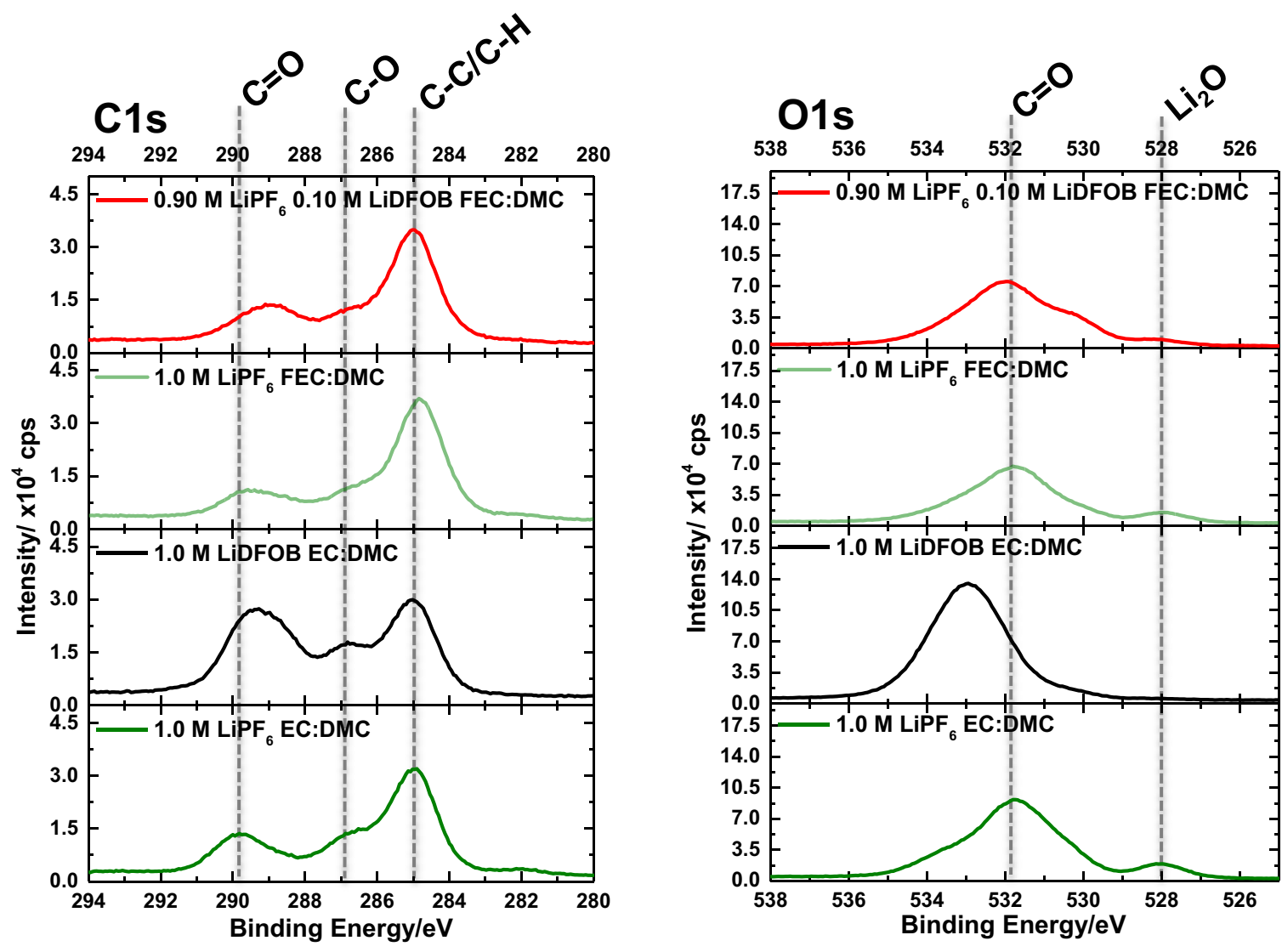

F1s

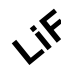

692691690689688687686685684683682681680

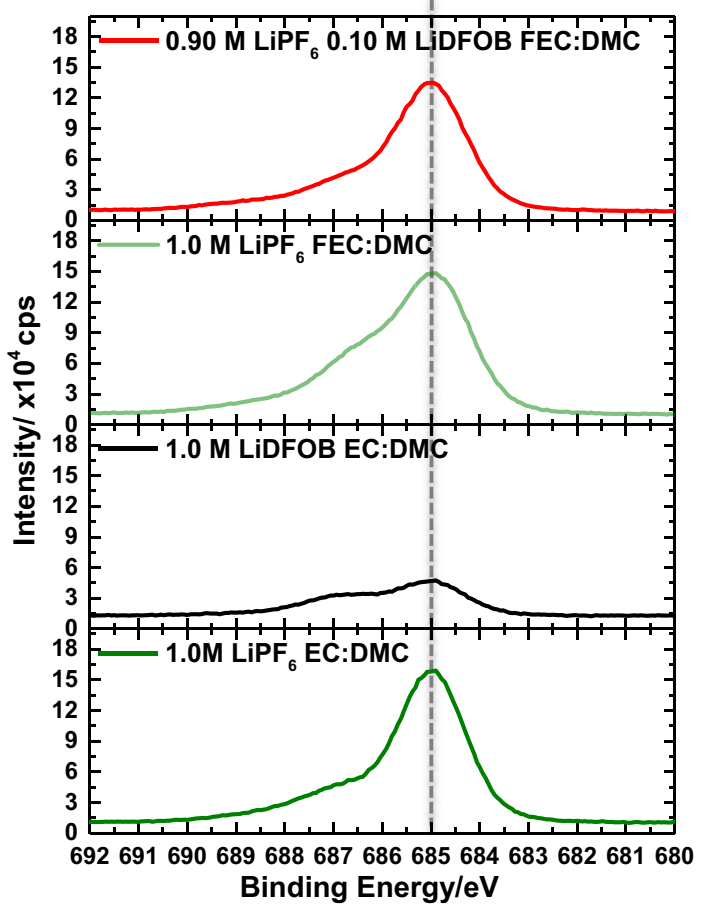

Figure 4. $\mathrm{C} 1 \mathrm{~s}, \mathrm{O} 1 \mathrm{~s}$, and F1s spectra of lithium metal plated with the investigated electrolytes. 

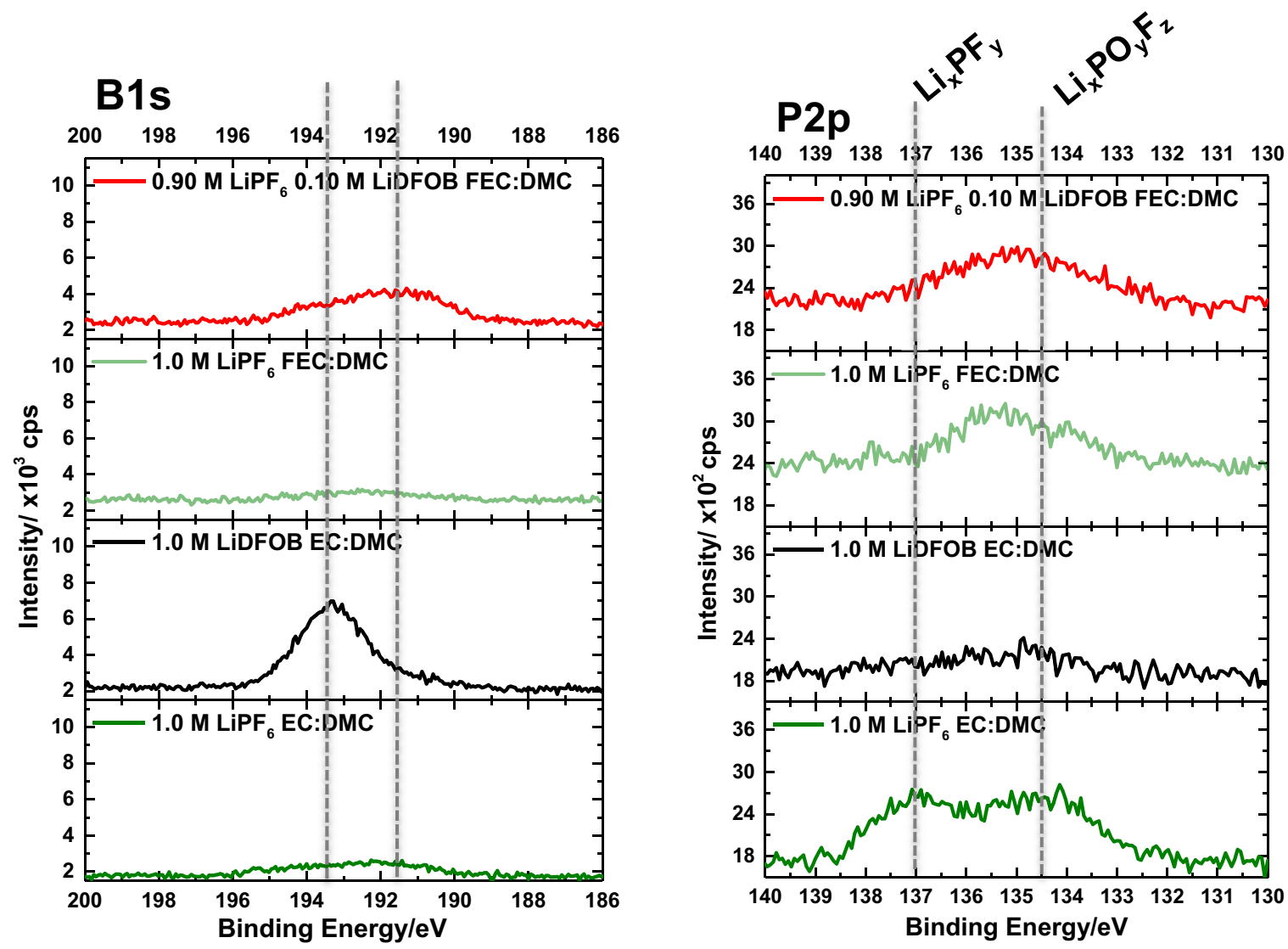

Figure 5. B1s and P2p spectra of lithium metal plated with the investigated electrolytes.

are observed at $193.4 \mathrm{eV}$ and $\sim 191.5 \mathrm{eV}$ in the $\mathrm{B} 1 \mathrm{~s}$ spectra for lithium plated from 1.0 M LiDFOB EC and 0.10 M LiDFOB FEC electrolytes, respectively. It should be noted that intensity from the P2s peak overlaps with B1s peak. However, the intensity of the P2p peak at $\sim 135.2 \mathrm{eV}$, characteristic of $\mathrm{Li}_{\mathrm{x}} \mathrm{PF}_{\mathrm{y}}$ and $\mathrm{Li}_{\mathrm{x}} \mathrm{PF}_{\mathrm{y}} \mathrm{O}_{\mathrm{z}},{ }^{18,19}$ is similar for both the 1.0 $\mathrm{M} \mathrm{LiPF}_{6}$ FEC and $0.10 \mathrm{M}$ LiDFOB FEC electrolytes, yet the intensity and peak position of the peaks the B1s spectra are different supporting the presence of boron decomposition products on the surface of lithium metal plated from the $0.10 \mathrm{M}$ LiDFOB FEC electrolyte. The shift in binding energy suggests that the boron containing species in the SEI differ in structure, but it is unclear at this time how the structures may differ. In addition, as expected the concentration of $\mathrm{B}$ is lower for the lithium plated with a lower concentration of LiDFOB. Overall, LiDFOB improves the electrochemical performance of the cells via modification of the SEI, confirming the synergistic behavior of LiDFOB and FEC for lithium metal electrodes.

\section{Conclusions}

The concentration of LiDFOB was varied in carbonate electrolytes to optimize the performance of the lithium metal anode in $\mathrm{Cu} \| \mathrm{LiFePO}_{4}$ cells. In EC electrolytes, LiDFOB is optimal in higher concentrations $(1.0 \mathrm{M})$, as the bulk salt. However, in FEC electrolytes, LiDFOB is optimal when used in lower concentrations, $0.05-0.10 \mathrm{M}$. Ex-situ surface analysis suggests that LiDFOB reacts on the surface of lithium metal to generate a more stable SEI improving the performance of lithium metal anodes in both EC and FEC-based electrolytes. Therefore, LiDFOB and FEC can be used in the electrolyte synergistically to optimize the performance of the lithium metal anode. This research demonstrates progress toward feasible high-energy density lithium-based batteries.

\section{Acknowledgment}

The authors thank BASF SE Electrochemistry Research Network for financial support.

\section{ORCID}

Zachary L. Brown (D https://orcid.org/0000-0003-0772-3159

Brett L. Lucht (D) https://orcid.org/0000-0002-4660-0840

\section{References}

1. P. Albertus, S. Babinec, S. Litzelman, and A. Newman, Nat. Energy, 3, 16 (2018). 2. X. Cheng, R. Zhang, C.-Z. Zhao, and Q. Zhang, Chem. Rev., 117, 10403 (2017).

3. B. Liu, J. G. Zhang, and W. Xu, Joule, 2, 833 (2018).

4. K. Xu, Chem. Rev., 104, 4303 (2004).

5. E. Peled, J. Electrochem. Soc., 126, 2047 (1979).

6. E. Markevich, G. Salitra, F. Chesneau, M. Schmidt, and D. Aurbach, ACS Energy Lett., 2, 1321 (2017).

7. I. A. Shkrob, J. F. Wishart, and D. P. Abraham, J. Phys. Chem. C, 119, 14954 (2015)

8. X. Fan, L. Chen, X. Ji, T. Deng, S. Hou, J. Chen, J. Zheng, F. Wang, J. Jiang, K. Xu, and C. Wang, Chem, 4, 174 (2018).

9. Z. L. Brown, S. Jurng, C. C. Nguyen, and B. L. Lucht, ACS Appl. Energy Mater, 1, 3057 (2018).

10. S. Jurng, Z. L. Brown, J. Kim, and B. L. Lucht, Energy Environ. Sci., 11, 2600 (2018).

11. Z. L. Brown, S. Jurng, and B. L. Lucht, J. Electrochem. Soc., 164, A2186 (2017).

12. C. C. Nguyen and B. L. Lucht, J. Electrochem. Soc., 161, A1933 (2014).

13. D. M. Seo, C. C. Nguyen, B. T. Young, D. R. Heskett, J. C. Woicik, and B. L. Lucht, J. Electrochem. Soc., 162, A7091 (2015).

14. G. V. Zhuang, K. Xu, H. Yang, T. R. Jow, and P. N. Ross Jr, J. Phys. Chem. B, 109, 17567 (2005)

15. G. V. Zhuang, H. Yang, P. N. Ross Jr., K. Xu, and T. R. Jow, Electrochem. Solid-State Lett., 9, A64 (2006)

16. G. V Zhuang, K. Xu, T. R. Jow, and P. N. Ross Jr, Electrochem. Solid State Lett., 7, A224 (2004).

17. M. Nie and B. L. Lucht, J. Electrochem. Soc., 161, A1001 (2014).

18. P. Verma, P. Maire, and P. Novák, Electrochim. Acta, 55, 6332 (2010).

19. A. M. Andersson, D. P. Abraham, R. Haasch, S. MacLaren, J. Liu, and K. Amine, J. Electrochem. Soc., 149, A1358 (2002). 